\title{
ELECTROPHYSIOLOGICAL TESTING OF DYSLEXIA
}

\author{
Miroslav Kuba ${ }^{1}$, Jana Szanyi ${ }^{1}$, David Gayer ${ }^{1}$, Jan Kremláček ${ }^{1}, Z_{u z a n a}$ Kubová ${ }^{2}$
}

Charles University in Prague, Faculty of Medicine in Hradec Králové: Department of Pathophysiology ${ }^{1}$, Department of Physiology ${ }^{2}$

Summary: We enlarged our previous study (Kubová Z. et al. Physiol Res 1995;44:87-89) giving an evidence about magnocellular pathway involvement (delayed motion-onset visual evoked potentials (M-VEPs)) in 70\% of dyslexic children. In the new group presented here, only $48 \%$ of 25 dyslexics displayed prolonged latencies of cortical responses to motion stimuli. However, there was no correlation of this defect with the used quantification of the reading skills (reading quotients). No significant EEG frequency spectrum changes were found. 10 subjects from the former group, who were re-examined 4 years after the previous study at the mean age of 14 years, exhibited significant shortening of the M-VEP latencies compared to the original values. Also in control subjects a distinct improvement in magnocellular pathway function was proved (in M-VEP re-examination after 4 years). These results document rather late maturation of the magnocellular pathway, which is evident mainly in dyslexic children. In both groups of dyslexics an effect of colour in moving stimuli was also tested to verify the reported effect of light wavelengths onto the magnocellular pathway function. However, no latency differences among grey, green, pink, yellow and blue stimuli were observed.

Key words: Dyslexia; Visual evoked potentials; EEG frequency spectrum; Magnocellular system; Motion

\section{Introduction}

Continuing search for etiological factors of dyslexia motivated also a lot of recent studies using various methods (PET, functional MRI, electrophysiology of the CNS, psychophysical examination) to verify the hypothesis of the visual magnocellular pathway involvement (5). There are quite new findings supporting the theories about a delayed signal transmission within the magnocellular pathway and/or a decreased activation of the visual association cortex - particularly of the medio-temporal (V5) area which is reported to be specialised for motion processing $(4,13)$. However, some other results $(7,14)$ are not in agreement with the opinion that quite large part of the dyslexic people has a deficit in visual functions. Since knowledge of the basis of dyslexia is crucial for strategy of its rehabilitation, we tried to enlarge our previous study (10) of motion related visual evoked potentials (VEPs) specifically testing the magnocellular pathway $(1,9)$ in dyslexic children. Simultaneously, we have tested whether the suspected visual deficit in dyslexics is attributable to a delay in magnocellular system maturation (according to some reports - e.g. by Barnard et al. (2)) and also if it is possible to influence the function of this system with the use of various light wavelengths (reported e.g. by Williams et al. (16) or Solan (11)).

\section{Methods and subjects}

Three groups of subjects were used for electrophysiological testing of visual function. We have examined 10 dyslexics (mean age $14.0 \pm 1.1$ years) from the group of 20 children who have been tested already 4 years ago (10) group No. 1 in Tab. 1. The second group consisted from 25 dyslexic children (mean age $10.0 \pm 1.9$ years) randomly selected in the $2^{\text {nd }}$ and $3^{\text {rd }}$ classes of a specialised school for dyslexics. In the third group 7 control subjects (normal readers of the mean age $13.7 \pm 1.1$ years) from the previous study (10) were repeatedly examined after 4 years interval. All subjects had visual acuity $6 / 6$ or better (with correction if needed).

The same set of VEPs examinations was done in each subject. Transient pattern-reversal visual evoked potentials (P-VEPs) were acquired with high contrast (96\%) squarewave black and white checkerboard (element size 40'). Two variants of motion-onset VEPs (M-VEPs) were used. The first one - linear motion (random order of fundamental directions, velocity $10 \mathrm{deg} / \mathrm{s}$ ) of low contrast (10\%) isolated checks (40' check size and 120' check-to check-distances) had grey, green, blue, yellow and pink modifications (equivalent wavelengths to recommendations by Wilkins et al. (15)). Second motion stimulus consisted of low contrast (10\%) grey concentric frames with increasing size and mo- 
tion velocity (centrifugal expansion) from the centre (fixation point) towards periphery (respecting the size of the retinal perception fields and sensitivity differences to motion velocity across the retina). Both moving stimuli had the same timing - $200 \mathrm{~ms}$ of motion were followed by $1 \mathrm{~s}$ interstimulus interval (stationary pattern). Visual stimuli for the VEPs testing were generated on a computer monitor (ViewSonic 21”, 100 frames/s, total display size 30x40 deg) with the mean luminance of $17 \mathrm{~cd} / \mathrm{m}^{2}$. With respect to uniform results to monocular and binocular stimulation in our previous study (10), only binocular VEPs were recorded in unipolar leads $\mathrm{Oz}, \mathrm{Or}, \mathrm{Ol}(5 \mathrm{~cm}$ to the right and left from the $\mathrm{Oz}$ ), $\mathrm{Cz}$ and $\mathrm{Fz}$ and in the bipolar lead $\mathrm{Oz}-\mathrm{Cz}$ with a sampling rate of $500 \mathrm{~Hz} .40$ epochs (sweeps) of $440 \mathrm{~ms}$ duration were averaged. Peak latencies and amplitudes of P100 in the P-VEPs and of the motion-specific N160 peak in M-VEPs (8) were evaluated. Data from the lead with maximum response (typically $\mathrm{Oz}$ in P-VEPs and $\mathrm{Ol}$ or Or in M-VEPs) are presented here.

Besides the VEPs, a frequency analysis of the resting EEG with eyes closed was accomplished in the new group of dyslexic children. 16 periodograms of 4 s epochs $(1 / 4 \mathrm{~Hz}$ resolution) were averaged (Bartlett's method (3)) and relative EEG "power" in theta and alpha bands as well as the "dominant frequency" were evaluated. Subsequently also IQ and reading quotient (number of correctly red words in one minute interval related to the age of the child) of these dyslexics were evaluated.

\section{Results and Discussion}

P-VEPs did not display any significant differences between the children and adult people as well as between the dyslexics and controls. It confirms our previous findings about an early maturation of the parvocellular pathway (10) predominantly activated by pattern-reversal stimulation (9) and gives another evidence about the intact parvocellular pathway in dyslexics.

The M-VEPs findings are summarised in Tab. 1 that covers also 4 years old data of the re-tested groups of dyslexics (No. 4) and normal readers (No. 5) for better comparison. Moreover, normal parameters of M-VEPs tested in healthy adult people (group No. 6) are also given. There was again (as it was in our previous study) a significant delay in responses to motion stimuli in dyslexics $(p<0.01)$, which is more evident in responses to expansion stimulation (abnormal latency in $48 \%$ of dyslexics) than in those to linear motion (delayed only in $20 \%$ of dyslexics). The "expansion" is more efficient motion stimulus because it activates several populations of direction-and velocity-sensitive cortical neurones simultaneously. (Expansion stimuli were not used in our previous examinations four years ago.)

Tab. 1: M-VEPs examination results.

\begin{tabular}{|c|c|c|c|c|c|c|c|c|}
\hline \multirow[b]{2}{*}{ Group } & \multirow[b]{2}{*}{$\mathrm{n}$} & \multirow[b]{2}{*}{ age } & \multirow[b]{2}{*}{$\begin{array}{l}\text { Reading } \\
\text { quotient }\end{array}$} & \multirow[b]{2}{*}{$\begin{array}{c}\text { Intelligence } \\
\text { quotient }\end{array}$} & \multicolumn{2}{|c|}{ M-VEPs (linear motion) } & \multicolumn{2}{|c|}{ M-VEPs (expansion) } \\
\hline & & & & & $\begin{array}{c}\mathrm{N} 160 \\
\text { latency } \\
{[\mathrm{ms}]}\end{array}$ & $\begin{array}{c}\text { N160 } \\
\text { amplitude } \\
{[\mu \mathrm{v}]}\end{array}$ & $\begin{array}{l}\mathrm{N} 160 \\
\text { latency } \\
{[\mathrm{ms}]}\end{array}$ & $\begin{array}{c}\text { N160 } \\
\text { amplitude } \\
{[\mu \mathrm{v}]}\end{array}$ \\
\hline $\begin{array}{l}\text { 1. Re-tested dyslexic } \\
\text { children }\end{array}$ & 10 & $14.0 \pm 1.1$ & $84.4 \pm 11.8$ & - & $\begin{array}{c}162.3 \pm 12.6 \\
272.5 \pm 34.8 \\
(n=4)\end{array}$ & $11.5 \pm 11.2$ & $\begin{array}{c}186.8 \pm 31.2 \\
271.3 \pm 7.0 \\
(n=3)\end{array}$ & $11.7 \pm 5.9$ \\
\hline $\begin{array}{l}\text { 2. Dyslexic children } \\
\text { - new group }\end{array}$ & 25 & $10.0 \pm 1.9$ & $78.8 \pm 9.9$ & $99.8 . \pm 8.3$ & $\begin{array}{c}173.2 \pm 20.6 \\
272.5 \pm 34.8 \\
(n=1)\end{array}$ & $10.7 \pm 5.5$ & $\begin{array}{c}182.3 \pm 33.6 \\
251.1 \pm 21.9 \\
(n=9)\end{array}$ & $14.8 \pm 6.4$ \\
\hline $\begin{array}{l}\text { 3. Re-tested normal } \\
\text { readers }\end{array}$ & 7 & $13.7 \pm 1.1$ & - & - & $\begin{array}{c}158.0 \pm 10.5 \\
214.0 \\
(n=1)\end{array}$ & $10.4 \pm 3.5$ & $\begin{array}{c}164.0 \pm 20.8 \\
260.5 \pm 12.6 \\
(n=4)\end{array}$ & $13.9 \pm 6.8$ \\
\hline $\begin{array}{l}\text { 4. Group of re-tested } \\
\text { dyslexic children } \\
\text { - results } 4 \text { years ago }\end{array}$ & 10 & $10.0 \pm 1.1$ & $86.7 \pm 9.4$ & - & $236.4 \pm 10.8$ & $8 \pm 2.3$ & - & - \\
\hline $\begin{array}{l}\text { 5. Group of re-tested } \\
\text { normal readers } \\
\text { - results } 4 \text { years ago }\end{array}$ & 7 & $9.7 \pm 1.1$ & - & - & $167.1 \pm 6.4$ & $7.9 \pm 1.6$ & - & - \\
\hline $\begin{array}{l}\text { 6. Normal adult } \\
\text { subjects }\end{array}$ & 25 & $25.1 \pm 9.3$ & - & - & $160.3 \pm 8.8$ & $8.4 \pm 5.8$ & $149.5 \pm 12.7$ & $11.4 \pm 5.4$ \\
\hline
\end{tabular}

The bottom values of the N160 latency represent the latter part of the split N160 peaks. Number of such cases is given in parentheses. 
In many cases, the pathology of the M-VEPs represents a splitting of the motion-specific negativity. The mean latency of the later peak is indicated below the first N160 peak value (number of such cases is given in parenthesis). This splitting can be interpreted as a partial deficiency of the magnocellular pathway with normal signal transmission in some fibres (channels). The higher incidence of pathological latencies (split N160 peaks) in expansion motion (having higher velocity in periphery of the stimulus field) might be explained as a predominant involvement of the hypothetical "high-velocity" channel. The rather low percentage of the pathological M-VEPs in the new dyslexic group (48\% - in "expansion" stimuli and $20 \%$ in linear motion) in comparison with the previous study ( $70 \%$ in linear motion) (10) indicates that the visual pathway deficit represents only one of the etiological factors responsible for dyslexia. Thus, its occurrence can vary substantially in small groups of randomly selected dyslexics (see e.g.(13)). Comparing the cumulated results in both groups of dyslexics, linear motion and "expansion" M-VEPs display about the same percentage of prolonged latencies $-42 \%$ and $48 \%$ respectively.

It seems that in some children from the new dyslexic group ( 4 out of 25) the diagnosis of dyslexia need not be appropriate. They had namely quite low value of IQ (below 90) and the criterion that the difference between the IQ and the reading quotient should be at least 20 (to exclude that the reading disability is not related to a mental retardation only) was not fulfilled. When we would exclude these subjects, the percentage of delayed M-VEPs in the new group would increase up to $57 \%$.

Comparison of the older re-tested dyslexics with the new group of dyslexics does not show significant decrease of the latencies dependent on the age. However, there is highly significant shortening $(\mathrm{p}<0.001)$ of the M-VEPs latencies in this older group when compared to the results from the time four years ago, which documents substantial maturation of the magnocellular pathway in dyslexics. Similar but non-significant shortening of latencies is visible also in the group of normal readers, indicating that the maturation of their magnocellular pathway is quicker in the lower age. Despite of the described improvement of M-VEPs latencies in dyslexic children, they have not reached the M-VEPs parameters of the age matched normal readers (including the occurrence of the split N160 peaks). This observation fits well with the persisting low values of the reading quotients in majority of the adolescent dyslexics, although we have not found any significant correlation between the reading quotients and M-VEPs parameters. This is explainable by the fact that the difficulty of the used reading tests increases with the age of subjects. (Note that the reading quotients in Tab. 1 staid about stable over the peri-

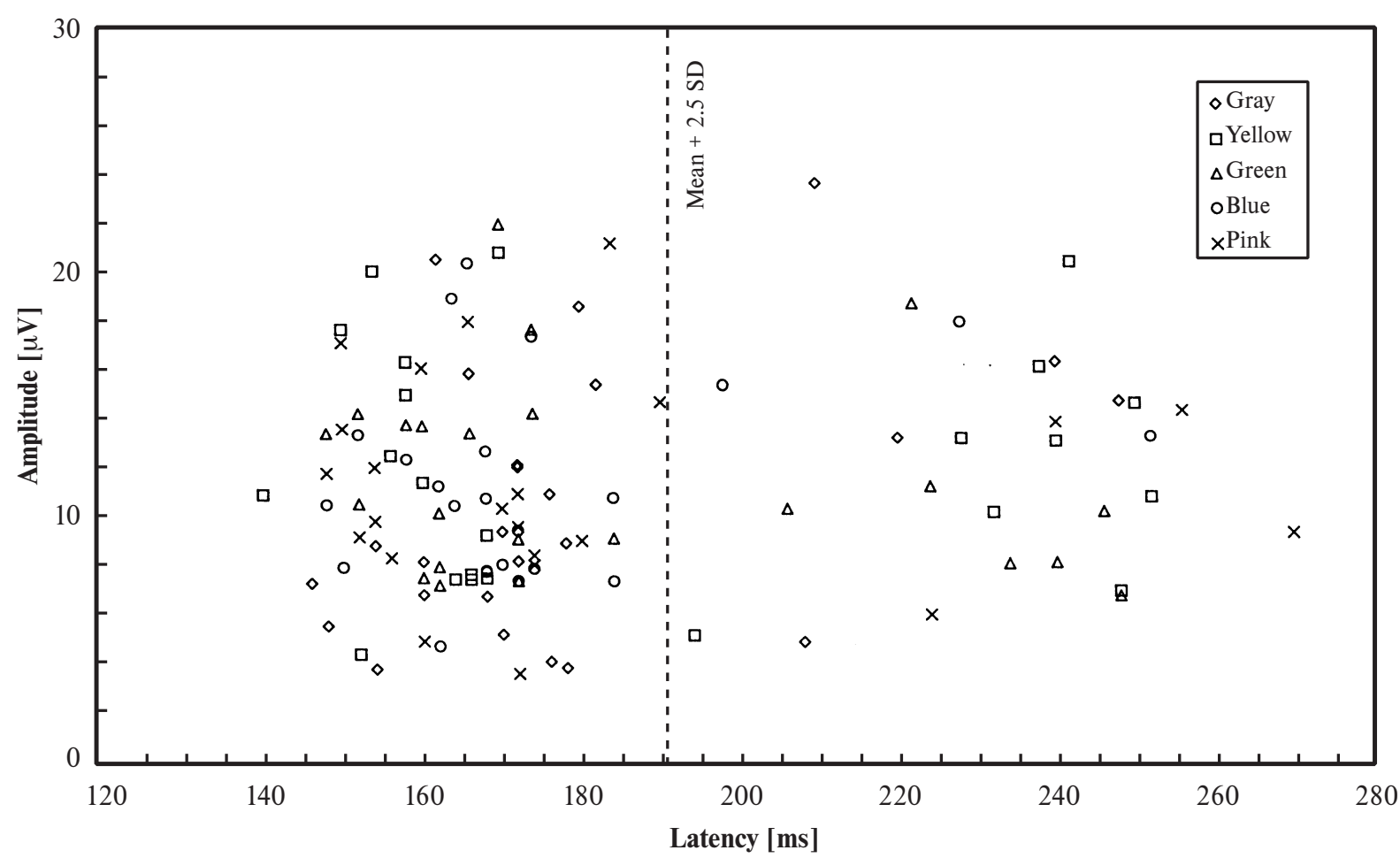

Fig. 1: Distribution of the N160 peak latencies ( $\mathrm{x}$ - axis) and amplitudes (y - axis) of the M-VEPs to linear motion of isolated checks in grey, green, blue, yellow and pink colour (constant luminance of $17 \mathrm{~cd} / \mathrm{m}^{2}$ and Michelson contrast of $10 \%$ ). Data from the group of 25 dyslexics are presented here. Vertical line represents an upper limit of the norm for M-VEPs latencies in age-matched normal readers (non-colour stimulus). 
od of four years.) Developmental theory of the "visual" variant of dyslexia fits well with the higher occurrence of this disorder among boys who are considered to have slower biological maturation in comparison with girls.

Manipulation with colours has not brought any significant effect onto the M-VEPs latencies. Nevertheless, the yellow colour increased significantly the M-VEPs amplitude in both groups of dyslexics. It is in agreement with a finding of Solman et al. (12), however, it does not support the former theory that blue colour filters reducing red light and contrast can improve reading - likely via a better function of the magnocellular pathway (e.g. 16,11). Comparison of M-VEPs parameters (including the latencies of the later part in case of the split N160 peaks) in grey and colour stimuli provides the scatter diagram in Fig. 1 (data from 25 younger dyslexics). It is evident that distribution of the N160 latencies, both of normal and pathological values, is independent on the stimulus colour.

Abnormal EEG frequency spectra parameters were found in only two (out of 25) dyslexics who displayed prevailing theta activity and the dominant frequency below $8 \mathrm{~Hz}$. Thus, we cannot confirm existing findings of significant EGG frequency spectra abnormalities in dyslexics (e.g. 6). No correlation between the EEG, VEPs parameters and reading quotients was proved. However, a positive correlation between IQ and EEG dominant frequency $(r=$ 0.53 ) in the group of younger dyslexics supports our above specified speculation that the relatively low rate of the pathological M-VEPs in this group can be caused by subjects with the low IQ who are incorrectly considered as dyslexics. Thus, in our continuing research much more attention must be paid to correct classification of dyslexic subjects.

\section{Conclusions}

1. M-VEPs examination enables to detect magnocellular pathway and/or temporal association cortex disorder in a subgroup of dyslexics.

2. This disorder might represent a delayed maturation of the visual system or of the association and cognitive brain areas as one of the etiological factors contributing to the reading disability.

3. The gained M-VEPs data do not support the theory about the influence of light wavelength onto the magnocellular pathway function.

\section{Acknowledgements}

This work was supported by the Grant MSM No. 111500001 .

\section{References}

1. Bach M, Ullrich D. Contrast dependency of motion-onset and pattern-reversal VEPs: Interaction of stimulus type, recording site and response component. Vision Res 1997;37:1845-9.

2. Barnard N, Crewther SG, Crewther DP. Development of a magnocellular function in good and poor primary school-age readers. Optom Vis Sci 1998;75:62-8.

3. Bartlett MS. Smoothing periodograms from time-series with continuous spectra. Nature 1948;161:686-7.

4. Demb JB, Boynton GM, Heeger DJ. Functional magnetic resonance imaging of early visual pathways in dyslexia. J. Neurosci 1998;18:6939-51.

5. Greatrex JC, Drasdo N. The magnocellular deficit hypothesis in dyslexia: a review of reported evidence. Ophthal Physiol Opt 1995;15:501-6.

6. Harmony T, Hinojosa G, Marosi E et al. Correlation between EEG spectral parameters and an educational evaluation. Intern J Neuroscience 1990;54:147-55.

7. Johannes S, Kussmaul CL, Muente TF, Mangun GR. Developmental dyslexia: passive visual stimulation provides no evidence for a magnocellular processing defect. Neuropsychologia 1996;34:1123-7.

8. Kuba M, Kubová Z. Visual evoked potentials specific for motion-onset. Doc Ophthalmol 1992;80:83-9.

9. Kubová Z, Kuba M, Spekreijse H, Blakemore C. Contrast dependence of motiononset and pattern-reversal evoked potentials. Vision Res 1995a;35:197-205.

10. Kubová Z, Kuba M, Peregrin J, Nováková V. Visual evoked potential evidence for magnocellular system deficit in dyslexia. Physiol Res 1995b;44:87-9.

11. Solan HA. The effects of varying luminance and wavelength on reading ability in good and poor readers: Is there a transient sytem deficit? Am Opt Assoc meeting, New Orleans, January 1996

12. Solman RT, Dain SJ, Lim HS, May JG. Reading-related wavelength and spatial frequency effects in visual spatial location. Ophthalmic Physiol Opt 1995;15:125. 32.

13. Richardson AJ. Handedness and visual motion sensitivity in adult dyslexics. The Irish J Psychol 1995;16:229-47.

14. Victor JD, Conte MM, Burton L, Nass RD. Visual evoked potentials in dyslexics and normals: failure to find a difference in transient or steady-state responses. Visual Neurosci 1993;10:939-46.

15. Wilkins A, Milroy R, Nommo-Smith I et al. Preliminary observations concerning treatment of visual discomfort and associated perceptual distortion. Ophthal Physiol Opt 1992;12:257-63.

16. Williams MC, Lecluyse K, Rock-Faucheux A. Effective interventions for reading disability. J Am Optom Assoc 1992;63:411-7.

Submitted September 2001

Accepted November 2001.

Doc. MUDr. Miroslav Kuba, CSc., Charles University in Prague, Faculty of Medicine in Hradec Králové, Department of Pathophysiology, Šimkova 870, 50001 Hradec Králové, Czech Republic. e-mail: kuba@lfhk.cuni.cz 